\section{Job Creation under Liquidity Constraints: The Spanish Case}

\section{Silvio Rendón*}

Universitat Pompeu Fabra

July 2000

* email: silvio.rendon@econ.upf.es. This paper is possible thanks to a Research Fellowship granted by the Bank of Spain. I thank the Servicio de Estudios Monetarios y Financieros for its motivating research environment, for several discussions on this subject and for providing the data. I thank Valeria Arza for excellent research assistance. All errors and omissions are mine.
Abstract.- This paper shows that liquidity constraints restrict job creation even when labor markets are flexible. In a dynamic model of labor demand, I show that in an environment of imperfect capital and imperfect labor markets, firms use temporary contracts to relax financial constraints. Evidence for the predictions of the model is presented using Spanish data from the CBBE (Central de Balances del Banco de España - Balance Sheet data from the Bank of Spain). It is shown that firms substitute temporary labor for permanent one and use less debt as their financial position improves. In particular, it is rejected that Spanish firms operate in an environment of free capital markets and of no labor adjustment costs. The labor reform of 1984, which created temporary contracts, implied to some extent a relaxation of liquidity constraints. Accordingly, firms used these contracts more extensively and used less debt; however, as capital markets continue to be imperfect, permanent job creation continues to be slow. Consequently, relaxation of liquidity constraints should also be part of a job creation strategy.

JEL Classification: J23, J32, E22, G31.

Keywords: Job Creation, Employment, Investment, Adjustment Costs, Liquidity Constraints. 


\section{Introduction}

The removal of labor market rigidities has been the cornerstone of labor policies in several European countries. The basic policy measures for labor market liberalization consisted in reducing firing and hiring costs, lowering government intervention in wage determination and in reducing unemployment transfers. However, firms in most European countries do not only work in an environment of imperfect labor markets, but also of imperfect capital markets. This paper shows that financial constraints restrict job creation even when labor markets are relatively flexible. While removing rigidities helps firms to create jobs and to increase capital accumulation by releasing internal resources for investment, binding liquidity constraints hinger job creation, especially for small firms. Capital market liberalization should, therefore, come together with labor market liberalization.

Among Western European countries, Spain has been the country with the largest unemployment rate, almost $20 \%$ for more than a decade. In 1984 a first labor reform was done to counteract the sharp increase in unemployment suffered during the 'transition phase' to a free economy. The basic change of this reform was to create a dual labor market system: a group of permanent workers that are difficult to hire, and especially difficult to fire; and a group of temporary workers that work on probation for three years. After these three years a worker has to be either promoted to a permanent worker or dismissed. After this reform, firms, especially the small ones, increased their hiring of temporary workers.

Using a dynamic model of labor demand under liquidity constraints, I show that by hiring temporary workers, firms are able to relax financial constraints, reduce their level of borrowing, and hedge against adverse shocks. The creation of permanent jobs, which are more productive but also more expensive, is limited by financial restrictions, especially for small firms. In this context, I evaluate two policy measures of partial flexibility. It is shown that in an economy populated mostly with small firms the removal of financial constraints implies more permanent job creation than the removal of labor market rigidities. With a full labor market liberalization but imperfect capital markets, firms can only expand capital and labor as their financial position improves. Job creation of small firms is slow, whereas big firms, for whom financial constraints are not binding, can afford to adjust faster to their desired level of capital and labor. When only labor markets are imperfect, small firms can adjust instantaneously to their desired level of capital and labor. They still have to pay adjustment costs, but the access to external resources relaxes the adverse effect of this rigidity. Because the financial position of big firms is already good, they do not benefit substantially from less constrained capital markets. In consequence, small firms gain more from capital market liberalization than from labor market liberalization, while the opposite is true for big firms. An economy that is populated mainly by small firms needs a labor policy that includes a relaxation of capital market constraints as part of a job creation strategy.

The research on the subject made so far deals with these issues separately. There is evidence that Spanish firms face significant financial constraints. Estrada \& Vallés (1995) find evidence that rejects the perfect capital market model and supports the existence of financial constraints. Moreover, these constraints are shown to be especially binding for small firms. Alonso-Borrego \& Bentolila (1994), in the same direction, find an important effect of financial variables on firms' investment. These findings have not been related to the employment problem in Spain. Moreover, perfect labor markets are implicitly assumed in these approaches. Similarly, labor market imperfections, in particular high labor adjustment costs, have been studied with similar methods to those used for understanding investment, but without any explicit link to capital market imperfections (Bentolila \& Saint-Paul 1992, Bover, Arellano \& Bentolila 1997).

The present paper proposes a framework to analyze these two issues jointly. It is a dynamic model where firms decide on a level of investment, permanent and temporary labor and debt subject to financial constraints, bankruptcy conditions and 
labor adjustment costs. The policy rules predicted by the model are estimated using in a fixed-effects specification. The data come from the CBBE (Central de Balances del Banco de España - Balance Sheet data from the Bank of Spain). It is noteworthy that this database has been used to analyze capital market imperfections, as well as labor market issues (Dolado \& Bentolila 1992, Bentolila \& Dolado 1993, Gómez \& Dolado 1995, Aguirregabiria \& Alonso-Borrego 1998). The trends described by these labor data are similar to those found using other databases, which shows that these data are credible. In particular, the hypotheses that Spanish firms operate in an environment of free capital markets and of no labor adjustment costs is rejected. Internal resources are found to be significant for capital accumulation and the demand of permanent workers. I also show that permanent employment exhibits a clear persistence and dependence on financial resources. Evidence is provided for the substitutability of permanent workers and of debt by temporary workers, caused by the reform of 1984 . The availability of temporary contracts allows firms to accumulate capital faster and to build their staff of permanent workers, reducing thereby the impact of debt on these variables.

The rest of the paper is organized as follows. In the next section the model is presented. A tractable simple version is described to gain intuition about the interaction between financial constraints and the choice of the labor contract. Thereafter, the model is extended to include capital, debt and a stochastic environment. Since this model does not have analytical solutions, several simulations are presented. Section 3 describes the data and some basic trends of them. Reduced form estimations are reported in Section 4. The main conclusions of this paper and possible extensions are summarized in Section 5.

\section{Model}

I will use a dynamic model of firm behavior, where firms are assumed to be intertemporal profit maximizers, i.e. they seek to maximize the discounted sum of the expected value of their future stream of dividends. As a way to provide intuition between the choice of the labor contract and financial constraints, I will start the exposition with a simplified deterministic model with permanent and temporary contracts. It is similar to the one proposed Bentolila \& Saint-Paul (1992) augmented to account for a dividend constraint. In a second step, a full-blown model with capital, debt and bankruptcy will be provided.

\subsection{Baseline Model}

The firm resides in a deterministic environment where it seeks to maximize the discounted stream or dividends, $D_{t}$, by choosing temporary $L_{t+1}$, and permanent workers $H_{t+1}$.

$$
\max _{H_{t+1}, L_{t+1}} \sum_{t=0}^{\infty}\left(\frac{1}{1+\rho}\right)^{t} D_{t},
$$

subject to the constraint that dividends be non-negative.

$$
D_{t}=x_{t}-c\left(H_{t}, H_{t+1}\right) \geq 0 .
$$

where $\frac{1}{1+\rho}$ is the discount rate and is assumed to be common for all firms. The constraint is interpreted as firms not being allowed to issue fresh equity. ${ }^{1}$ Dividends consist of the financial resources of the firm, $x_{t}$, net of labor adjustment costs. The labor adjustment cost function is assumed to be linear:

$$
c\left(H_{t}, H_{t+1}\right)=\left\{\begin{array}{lll}
C \times\left(H_{t+1}-\gamma H_{t}\right), & \text { if } & H_{t+1}>\gamma H_{t} ; \\
0, & \text { if } & H_{t+1}=\gamma H_{t} \\
F \times\left(\gamma H_{t}-H_{t+1}\right), & \text { if } & H_{t+1}<\gamma H_{t} .
\end{array}\right.
$$

\footnotetext{
${ }^{1}$ Asymmetric information can make equity finance expensive for firms. Potential lenders, ignoring the quality of the firm, demand an equity premium, which makes external finance more expensive than internal funds (Myers \& Majluf 1984, Greenwald, Stiglitz \& Weiss 1984).
} 
$C$ is the hiring cost, and $F$ is the firing cost, both in terms of unit variation in employment. Workers are exogenously separated from their jobs at rate $\gamma \leq 1$ without implying any extra cost for employers. Financial resources are defined as

$$
x_{t}=\theta\left(H_{t}+\lambda L_{t}\right)^{\beta}-w_{H} H_{t}-w_{L} L_{t}
$$

that is, as revenues net of labor costs. Revenues are given by a production function with constant technology parameters $\theta$ and $\beta$, which depend on efficiency units of labor. $\lambda$ is the efficiency unit of a temporary worker in terms of a permanent one. Temporary workers are assumed to be less productive than permanent ones, that is, $\lambda<1 . w_{i}, i=\{H, L\}$ are the wage rates for each type of worker.

It is possible to express this problem by a Bellman equation,

$$
V\left(x_{t}, H_{t}\right)=\max _{H_{t+1}, L t+1}\left\{x_{t}-c\left(H_{t}, H_{t+1}\right)+\frac{1}{1+\rho} V\left(x_{t+1}, H_{t+1}\right)\right\},
$$

subject to (2).

The only reason why financial resources represent an additional state variable in this problem is that the initial amount of temporary workers may not be the optimal one. As shown below, temporary labor can be determined as a function of permanent labor. Writing the problem in terms of financial resources, however, has the advantage of giving additional intuition for this problem in connection with further extensions where capital and debt are included. Given the structure of the problem, the following assumptions are needed to produce meaningful results.

Assumption $1: w_{H}>w_{L}$.

Assumption 2: $w_{L}>\lambda w_{H}$.

Assumption 1 states that permanent workers have higher wages than temporary ones while Assumption 2 postulates that permanent workers are more profitable than temporary ones. The labor cost of the efficiency units of the former is lower than the one of the latter. The idea behind this last assumption is that permanent workers acquire specific human capital. A temporary worker has a higher turnover over firms, is relatively new in the firm, and, consequently, is a low- skilled worker. From a cost-benefit analysis, a firm benefits more from employing workers longer. If firms did not face a dividend constraint, that is, if capital markets are free, they would jump immediately to the optimal level of permanent employment, which in this case it is represented by a corridor. The result of solving the two first order conditions yields three possible cases for the desired level of permanent workers:

$$
\begin{aligned}
& H_{t+1}^{F C M}= \begin{cases}H^{C}, & \text { if } \gamma H_{t}<H^{C} ; \\
\gamma H_{t}, & \text { if } H^{C}<\gamma H_{t}<H^{F} \\
H^{F}, & \text { if } \gamma H_{t}<H^{F}\end{cases} \\
& \text { where } \quad H^{C}=\left(\frac{\theta \beta}{w_{H}+(1+\rho-\gamma) C}\right)^{\frac{1}{1-\beta}} ; H^{F}=\left(\frac{\theta \beta}{w_{H}-(1+\rho-\gamma) F}\right)^{\frac{1}{1-\beta}} .
\end{aligned}
$$

If the firm has too many permanent workers, it goes immediately to $H^{F}$. Once that is done, it just allows them to quit until it reaches $H^{C}$, where it does not change its labor force anymore. If the firm has too few permanent workers, it jumps to $H^{C}$, where it stays.

Since the choice variable, $L_{t+1}$, does not show up in the constraint Equation (2), an explicit solution is attained for temporary employment as a function of contemporaneous permanent employment,

$$
L_{t+1}^{*}\left(H_{t+1}\right)=\left\{\begin{array}{l}
\frac{1}{\lambda}\left(\left(\frac{\theta \lambda \beta}{w_{L}}\right)^{\frac{1}{1-\beta}}-H_{t+1}\right), \text { if }\left(\frac{\theta \lambda \beta}{w_{L}}\right)>H_{t+1} ; \\
0, \text { otherwise. }
\end{array}\right.
$$

It is clear that the more permanent workers a firm can afford to hire, the fewer temporary workers that the firm will hire. One can see from Equations (5) and from the condition of Equation (6) that, depending on parameter values, temporary workers may be hired at steady states or, on the contrary, temporary workers are just hired during dynamics toward steady state.

$$
\begin{aligned}
L^{*}\left(H^{C}\right) & >0, \text { if } & & w_{H}+(1+\rho-\gamma) C>\frac{w_{L}}{\lambda} ; \\
& =0, & & \text { otherwise. }
\end{aligned}
$$


It is clear that for a level of permanent workers $H^{F}$ there won't be any temporary workers, because of Assumption 2. In this context, the only reason why the firm does not attain the optimal level of permanent workers is because it is hitting the constraint (2) on dividends. This defines the policy rule for permanent workers,

$$
H_{t+1}=\left\{\begin{array}{lll}
\min \left(\frac{x_{t}}{C}+\gamma H_{t}, H^{C}\right), & \text { if } \gamma H_{t}<H^{C} ; \\
\gamma H_{t}, & \text { if } H^{C}<\gamma H_{t}<H^{F} ; \\
\max \left(-\frac{x_{t}}{F}+\gamma H_{t}, H^{F}\right), & \text { if } \gamma H_{t}>H^{F} .
\end{array}\right.
$$

These policy rules, both for permanent and for temporary workers, are illustrated in Figure 1. Permanent workers next period depend on permanent workers in the current period and on internal resources. If firms just start and have $x_{t}=0_{+}$, they cannot pay adjustment costs. In that case, their level of permanent workers does not change and their policy rule with respect to permanent workers is just a 45-degree line. In that case firms that do not have enough permanent workers hire temporary workers. Even a firm with $H_{t}=0$, can hire temporary workers and have a positive amount profits next period. Therefore, it is clear that temporary workers allow firms to accumulate internal resources and permanent workers faster. The richer the firm, the greater its adjustment in permanent employment and the fewer temporary workers they need to hire. In models of adjustment costs with perfect capital markets, adjustment outside the bounds of the corridor happens immediately; inside the corridor there is an 'inaction zone' (Caballero 1997). Here, immediate adjustment only takes place for $x_{t}$-rich firms. For $x_{t}$-poor firms adjustment takes place slowly, as there are borrowing constraints.

If financial markets are perfect, there is action only within the corridor $\left[H^{C}, H^{F}\right]$, depending on initial conditions, only summarized by $H_{t}$. In that case, $x_{t}$ ceases to be a state variable. Any initial condition outside the corridor will lead to an immediate jump to the borders of the corridor. With imperfect capital markets, there is slow convergence to the borders. We can also compare the case when there are free capital markets only with the case of free labor markets only. As shown in Equation (5), if capital markets are perfect there will be an immediate jump to the borders.

If there are perfect labor markets, that is, no firing or hiring costs, there will no corridor but a unique solution, and of course $H_{t}$ and $x_{t}$ are no longer state variables:

$$
H_{F L M}=\left(\frac{\theta \beta}{w_{H}}\right)^{\frac{1}{1-\beta}}
$$

In both cases, there will be immediate convergence to the desired level of permanent workers, however, it is clear that

$$
H_{F C M}^{C}<H_{F L M}<H_{F C M}^{F} .
$$

Therefore, the assessment of any policy measure depends crucially on initial conditions, that is, if the economy is in a "growth" or in a "down sizing" dynamics. Permanent employment is higher under labor liberalization than under financial liberalization if there is too little permanent employment. If there is too much permanent employment the opposite is true. In both cases, no temporary workers are hired. Another important difference is that under labor market liberalization, firms jump to their desired level of permanent employment by not paying any adjustment cost, whereas with financial liberalization they do. It is just that they have negative dividends for one period. That is, in present value terms, firms are better off when there is free labor markets even if financial markets are imperfect.

\subsection{Full-blown model}

In the simple model shown, liquidity constraints become binding only because of adjustment costs of permanent workers, as labor is the only factor of production. If these adjustment costs are removed, there is no reason for liquidity constraints to be binding. One would like to make the same policy comparison when there is also capital, so that removing adjustment costs is not equivalent to a complete relaxation of liquidity constraints. The next step is thus to extend the model with capital and a maximum level of debt. The model proposed here is a neo-classical model of 
investment on the lines of Jorgenson (1963), extended to include hiring and firing decisions (in a similar way as the one done by Bentolila \& Saint-Paul (1992)) as well as liquidity constraints and bankruptcy conditions (Gross 1994).

The firm uses now two inputs, capital and efficiency units of labor, in the production process. As before, it maximizes the discounted stream of dividends, by choosing investment, both types of labor, and borrowing. Define its financial resources $x_{t}$ as the sum of profits and undepreciated capital less debt repayments in the current period, i.e.,

$$
x_{t}=\theta_{t} K_{t}^{\alpha}\left(H_{t}+\lambda L_{t}\right)^{\beta}+(1-\delta) K_{t}-w_{H} H_{t}-w_{L} L_{t}-(1+r) B_{t} .
$$

Revenues are now given from a Cobb-Douglas production function which depends on capital $K_{t}$ and efficiency units of labor. The firm operates in a risky environment, which is captured by a stochastic shock $\theta_{t}$ that affects its profits (and therefore, its financial position). The value of the shock is observed each period and the employment, investment and borrowing decisions are made accordingly, subject to the constraints described above. $\theta_{t}$ follows a Markov process $\Gamma\left(\theta_{t+1} \mid \theta_{t}\right)$ with mean $\mu_{t+1}\left(\theta_{t}\right)$. Capital depreciates at a rate $\delta$ while the non-depreciated part remains in the firm. The capital stock at time $t+1$ has the following law of motion

$$
K_{t+1}=(1-\delta) K_{t}+I_{t}
$$

Financial resources are net from any previous debt $B_{t}$ which is paid at the interest rate $r$. Therefore, dividends are

$$
D_{t}=x_{t}-K_{t+1}+B_{t+1}-c\left(H_{t}, H_{t+1}\right) \geq 0
$$

As before, dividends are constrained to be nonnegative. Additionally, firms can go bankrupt, that is, if they cannot meet their current obligations out of their current assets, they shut down forever. Formally, the firm is in the market only if

$$
x_{t}>0
$$

Lenders, who observe that firms can go bankrupt, are willing to supply firms with external resources only if firms' internal resources are expected to be positive, that is $E\left(x_{t+1} \mid x_{t}, H_{t}, \theta_{t}\right)>0$. The implication of this condition is that firms cannot borrow more than an amount that would cause them to go bankrupt in expected value in the next period. $B_{t+1}$ must therefore satisfy the following condition:

$$
(1+r)^{-1}\left(\mu_{t+1} K_{t+1}^{\alpha}\left(H_{t+1}+\lambda L_{t+1}\right)^{\beta}-w_{H} H_{t+1}-w_{L} L_{t+1}+(1-\delta) K_{t+1}\right)>B_{t+1}
$$

At period $t$ a firm enters with a given capital stock $K_{t}$, a labor force level $H_{t}$ and $L_{t}$ and debt $B_{t}$. When the shock $\theta_{t}$ is realized, financial resources $x_{t}$ are determined. Given that shock, the corresponding amount of financial resources, and permanent employment $H_{t}$, the firm chooses its capital stock $K_{t+1}$, labor force $H_{t+1}, L_{t+1}$ and a level of debt $B_{t+1}$, for the next period, conditional on the constraints. Consequently, the Bellman equation can be written as

$V\left(x_{t}, H_{t}, \theta_{t}\right)=\max _{K_{t+1}, H_{t+1}, L_{t+1}, B_{t+1}}\left\{x_{t}-K_{t+1}-c\left(H_{t}, H_{t+1}\right)+B_{t+1}+\frac{1}{1+\rho} E V\left(x_{t+1}, H_{t+1}, \theta_{t+1}\right)\right\}$

subject to condition (12) and constraints (11), and (13).

The solution to this problem is contained in four policy rules

$$
\begin{aligned}
K_{t+1} & =K_{t+1}\left(x_{t}, H_{t}, \theta_{t}\right), \\
H_{t+1} & =H_{t+1}\left(x_{t}, H_{t}, \theta_{t}\right), \\
L_{t+1} & =L_{t+1}\left(x_{t}, H_{t}, \theta_{t}\right), \\
B_{t+1} & =B_{t+1}\left(x_{t}, H_{t}, \theta_{t}\right) .
\end{aligned}
$$

This model does not admit an analytical solution, which means that numerical solutions have to be pursued.

\subsection{Simulation}

I compute a numerical solution for assigned parameter values by discretizing the state space (all possible combinations of $K, H, L$, and $B$ ) into a grid of points. Starting 
with an arbitrary initial value for the value function $V(\cdot)=V_{0}$, (equal to 0 in this case), Equation (14) is maximized with respect to $K, H, L$ and $B$ to get the policy functions associated with $V_{0}, K_{0}, H_{0}, L_{0}$, and $B_{0}$. Using these policy functions, a new value function is computed. This procedure is repeated until the value function converges. The shock is parameterized as a simple autoregressive process with two values, high $\theta$ and low $\theta$ with a Bernoulli distribution:

\begin{tabular}{l|l|l}
\hline \hline & $\underline{\theta}$ & $\bar{\theta}$ \\
\hline$\underline{\theta}$ & $p$ & $(1-p)$ \\
$\bar{\theta}$ & $(1-q)$ & $q$ \\
\hline \hline
\end{tabular}

The parameter values used in this simulation are given below:

\begin{tabular}{ll|ll}
\hline \hline$\alpha=$ & 0.2 & $\beta=$ & 0.4 \\
$\rho=$ & 0.01 & $r=$ & 0.064 \\
$\delta=$ & 0.12 & $\gamma=1$ \\
$C=$ & 0.9 & $F=$ & 0.9 \\
$w_{H}=$ & 0.4 & $w_{L}=$ & 0.35 \\
$\lambda=$ & 0.7 & \\
$\underline{\theta}=$ & 1.8 & $\bar{\theta}=2$ \\
$p=$ & 0.7 & $q=$ & 0.5 \\
\hline \hline
\end{tabular}

These parameters are based on estimation results presented by Pratap \& Rendón (1998). The share of capital, $\alpha$, as it is usually the case, it is calibrated to be one third and the one of labor, $\beta$, two thirds. However, to introduce the necessary curvature to have a solution, the parameters are chosen so that $\alpha$ and $\beta$ add up to 0.6 , as in models of capital only. $\rho$ and $r$ are chosen so that external resources are more expensive than internal ones. That way firms have an incentive to use external resources to grow only, but to use internal resources once they are big. The deprecation rate is assumed to be $12 \%$ as in other calibrations. To simplify the analysis, I assume no exogenous separations $(\gamma=1)$ and no asymmetries in firing and hiring costs $(C=F)$. These adjustment costs are relatively high compared to the wage rates, and represent an incentive to use temporary labor. Assumptions 1 and 2 are satisfied by the choice of $w_{H}, w_{L}$ and $\lambda$, that is, abstracting from adjustment costs, permanent workers are more profitable than temporary ones. The process for the shock implies that there is more persistence in the low state, than in the high state, which makes firms cautions with external finance.

The results of these simulations are provided in Figure 2, which represents the case when both financial markets and labor markets are imperfect (Liquidity Constraints: $D_{t} \geq 0$; Adjustment Costs: $C>0, F>0$; "LC-AC"). It presents the four policy rules with respect to $x_{t}$ and $H_{t}$ for a high value of the shock. Firms with a weak financial position, represented by a low value of $x_{t}$, increase their capital stock only as $x_{t}$ grows However, after $x_{t}$ reaches a sufficiently high level, the firm is able to hold the desired level of capital, so capital is not sensitive to $x_{t}$ anymore. In this model, unlike other models with no labor (or perfect labor markets and one type of labor), the desired level of capital depends as well on the amount of permanent workers in the firm. In a certain way, as it is a complementary factor, capital reproduces the policy rule shown by permanent labor. In Figure 2, permanent workers have a similar policy rule as in Figure 1. When financial resources $x_{t}$ are big, the firm adjust permanent workers immediately to any of the bounds. When financial resources $x_{t}$ are small, the dividend constraint is binding and the firm does not adjust permanent labor immediately. If the firm has too many permanent workers, the adjustment process consists in getting rid of these workers. However, as borrowing constraints are present, the firm has to commit its own resources for this enterprise, finding optimal to borrow to finance it. If the firm has too few permanent workers, the adjustment toward the desired level of permanent workers is slow and irregular. This shape is explained because firms are using debt to increase both capital and permanent labor and, on the other hand, because there is a dynamics of substitution of temporary workers for permanent ones. Debt is shown to have the inverted U-shape, typical in other investment models. As 
capital stock as a function of $x_{t}$ moves closer to its desired level, $B_{t+1}$ falls to zero. It is noteworthy that for firms with no binding constraint, the level of all these variables is fixed, that is, an increase in financial resources does not affect at all any of these variables. Debt is also shown to be increasing in permanent labor, even for small values of $x_{t}$. The reason for that is that as $H_{t}$ grows, so does capital, determining thereby a relatively high borrowing limit, as it is shown in Equation (13).

In the same way permanent labor is shown to increase as the financial position of the firm improves, temporary labor, in contrast, increases for low values of $x_{t}$, and decreases for higher values of $x_{t}$. There are two counteracting effects in determining this path of temporary labor. Capital is increasing which pulls temporary labor up for a while. Firms with low internal financial resources avoid paying adjustment costs to permanent labor and hire instead temporary workers. On the other hand, permanent labor goes up as well, which brings temporary labor down. That implies that temporary workers follow a function which is an inverted U-shape in $x_{t}$, and monotonically decreasing in $H_{t}$. This implies debt as well as temporary workers show an inverted U-shape in permanent workers.

Once the optimal solution in the presence of both constraints is characterized, one can try to perform the same policy simulations done in the previous subsection 2.1. A policy of fully liberalizing labor markets means to remove adjustment costs and with them the dual labor market structure. As said, in this extended model, this policy does not automatically avoid that the liquidity constraint becomes binding, as capital and debt are also present. Figure 3 reports the results of this simulation for the four policy rules (Liquidity Constraints: $D_{t} \geq 0$; Adjustment Costs: $C=0, F=0$; "LC-NAC"). The basic effect of this policy is that permanent labor is no longer a state variable. The outcome of the simulation is similar to that of investment models with where labor is not explicitly modeled. By Assumption 2, no temporary worker is hired, only permanent workers. Employment, as capital and debt, is affected by the financial position of the firm. It can be seen that permanent labor (or only employment) jumps faster toward its optimal level, as the liquidity constraint (2) does not affect directly labor as it does capital. That is why capital increases slowly and pulls labor up to a certain desired level. Debt exhibits an inverted U-shape in financial resources. It is fully used to finance investment. This simulation shows that even with a full liberalization of labor markets there is no immediate adjustment in permanent labor, as it depends crucially on financial resources.

An alternative policy is to remove financial constraints, that is, relax the dividend constraint, but leaving positive adjustment costs. This means a liberalization of capital markets; the corresponding four policy rules are shown in Figure 4 (No Liquidity Constraints; Adjustment Costs: $C>0, F>0$; "NLC-AC"). In this case, internal financial resources $x_{t}$ cease to be a state variable; only $H_{t}$ determines the policy rules. There is no need to incur in debt, which is expensive, so debt is zero for any state. Similarly, since firms now can pay their adjustment costs out of equity, they can immediately adjust to their desired level of capital and permanent labor. Now, optimal capital and labor have a similar form. For both factors, there is an immediate jump toward an upper and lower bound depending on the current level of permanent workers. This looks like models of adjustment costs with dynamics inside the 'inaction zone'. Like labor market liberalization, this policy eliminates the dual structure of the labor market, producing immediate jumps both in capital as in labor. It does not eliminate the 'thick' desired level of both factors. That is there is a size distribution of firms, but only inside the corridor, unlike the previous case, where there is a size distribution which depends on internal resources and covers a wider domain. In this model the only way to have an immediate jump to a unique desired level of capital and permanent labor is to liberalize both markets, as it is the case in Figure 5 (NLC-NAC).

In the same way as in subsection 2.1, one would like to compare the two exclusive policies (LC-NAC vs. NLC-AC). Although they both have a positive effect on job creation, their comparison depends crucially on the parameter values, especially on 
the values of hiring and firing costs. A big corridor implies a lower steady state regardless of financial resources and of employment. Removing adjustment costs means more permanent jobs and less temporary ones, but employment still will depend on financial resources, and firms will have to increase employment as they increase their financial position. On the other hand, with no liquidity constraints and positive adjustment costs, even financially poor firms will be able to create jobs very fast. Consequently, the optimal policy will depend crucially on the employment and internal financial resources distribution of firms. If the economy is predominantly populated with financially rich firms, then adjustment costs are relatively more damaging, as it lowers optimal employment. If the economy is predominantly populated with financially poor firms, then it is more important for them to have financial constraints removed so they grow faster. In a way, in Lucas's terms, it is a trade-off between a 'growth-effect' and a 'level-effect.' In the Spanish case, the policy adopted to create more employment has been to introduce temporary contracts. Although that meant an alleviation of the need to pay adjustment costs, liquidity constraints continue to slow down job creation for financially poor firms.

\section{Data}

The data come from the database of balance sheet records kept at the Bank of Spain (Central de Balances del Banco de España - CBBE). This dataset contains 94192 observations for more than 200 variables about the financial structure as well as employment of 19473 firms from 1983 until 1996. I conducted a selection of the data, leaving in the sample manufacturing private firms that do not change activity, do not merge or split and have more than five consecutive observations. This selection also excludes firms with observations that have negative or zero gross capital formation. That means that these are firms whose capital is growing. A further description of the selection of the data is provided in the Appendix. The final sample consists of
1380 firms with 12336 observations.

Table 1 presents descriptive statistics for the main variables in original amounts, ratios and variations. The data are given in millions of pesetas of 1987. These table gives an idea about the values of the variables, as well as how variables behave according to size. It is clear that in original values all variables are increasing in size. However, if we see their behavior in ratios, we can distinguish clear trends in size. Internal resources per capital do not exhibit big variation according to size, but the debt-capital ratio clearly decreases in size. Big firms have a lower level debt with respect to their level of capital than small ones. With respect to workers, big firms have almost twice as much internal resources and capital per workers as small firms. However, debt per worker does not differ substantially between small and big firms: 1.98 for small firms and 2.26 for big ones. What it is clearly different is the difference between the percentage of temporary workers in the labor force. Small firms have a higher percentage of temporary workers (15\%) than big firms (7\%). Investment rates of small firms, or growth rates of capital are slightly higher for small firms, $21.8 \%$, against $18.1 \%$. As this sample is constructed excluding firms with nonpositive levels of investment, this is not surprising. What is noteworthy is that total employment goes down over time, precisely given the selection that leaves in the sample firms whose capital is growing. One can see that there is a net decrease of total employment, at $.57 \%$ yearly, mostly explained by the net destruction of permanent jobs by big firms at an annual rate of $-2.17 \%$. Although this reduction was partially compensated by their increase of temporary employment at an annual rate of $1.23 \%$, most of temporary job creation is explained by small firms, which increased it at an annual rate of $5.13 \%$. Small firms were also able to increase net permanent job creation slowly, at $0.25 \%$ annually. It is clear that these data show a dynamics of substitution of permanent for temporary jobs inside big firms, and from big firms to small firms.

Growth rates of capital growth show a greater persistence than growth rates of employment growth. For capital, growth rates show an autocorrelation of 0.31 for 
small firms, and of 0.51 for big firms. In contrast to that, the autocorrelation for total employment is low, especially for small firms, which show 0.0095 . The corresponding number for big firms is 0.1680 . This low persistence in net job creation can be explained by the fact that this was period of change in the labor force. The dynamics of substitution of permanent by temporary labor was mainly concentrated in small firms, whereas big firms managed to have more persistence in employment growth.

Out of these variables, I focus on the behavior of the percentage of temporary workers and on the debt-capital ratio over time and over size. Table 2 describe the trend of temporary workers as a percentage of the labor force over time and by firm size. It clearly shows that after the labor reform of 1984 that created temporary contracts, firms increased the percentage of temporary labor over the labor force. Temporary employment increased participation in the labor force from $3.95 \%$ in 1984 to $12.35 \%$ in 1996 . This increase is especially important for small firms. Those firms with less than 50 workers in 1996 had $21.51 \%$ of their workers with temporal contracts. Big firms, those with more than 1000 workers, on the contrary had only $4.42 \%$ of their labor for under those contracts. In a way, the percentage of temporary workers according to size, in particular for the last year of the sample, depicts an inverse U-shape curve, as in the theoretical model. It is, therefore clear, that temporary contracts are more important for relatively small firms (less than 100 workers) than for bigger firms. When firms grow bigger they tend to hire relatively more permanent workers, as the baseline and extended model predict. A big firm must, consequently, have an incentive to prefer permanent over temporary workers.

Table 3 shows the debt capital ratio over time and for each firm size. ${ }^{2}$ It shows that firms decrease their debt over time. The debt-capital ratio decreases from 0.74 in 1984 to 0.36 in 1996. That means that firms are using less debt in terms of the collateral they have. It also shows that bigger firms borrow relatively less than small

${ }^{2}$ Debt refers to short term debt which is the one that is usually used to attend short term fluctuations in cash flow. ones. Firms with less than 50 workers have a debt-capital ratio of 0.60 in 1996 , whereas big firms with more than 1000 workers have a debt-capital ratio of 0.33 in that same year. In a similar way as temporary labor over the labor force, the debtcapital ratio exhibits an inverse U-shape curve, as in the theoretical model. Hence, small firms are those that borrow relatively more and those that use relatively more temporary contracts. This corresponds to the theoretical implication that small firms are growing and, accordingly, they need more external resources and cannot afford to hire permanent workers. Big firms have so much internal resources that they do not need to borrow, so they can afford to hire permanent workers. Looked over time the relationship between temporary hiring and debt seems to be inverse. This can be seen as a comparative statics change, where the creation of temporary contracts substitutes the need for debt. That is, however, a sensible conjecture suggested by a first glance at the data, rather than a conclusion. In the next section, several estimations are presented for a further clarification of this issue.

\section{Estimation}

To assess whether the relationships predicted by the model hold in the data, I present reduced form estimations for $K_{t+1}, H_{t+1}, L_{t+1}$ and $B_{t+1}$ as a function of the state variables, $x_{t}$ and $H_{t}$. To account for idiosyncratic persistent shocks $\theta_{t}$, I perform a fixed effects regression for each of the policy rules. Since there is a wider use of temporary contracts after 1984, I split the sample in observations of 1987 and before, and in observations after 1987. The idea is to compare the period when the labor reform started with the period when the reform was fully established, and check if there is evidence for a relaxation of borrowing constraints because of the introduction of temporary contracts. Since the policy rules are nonlinear and have discontinuities, these regressions are done by pieces, depending on the level of internal resources $x_{t}$ and of permanent workers $H_{t}$. These cutoffs are clearly arbitrary and are only 
meant to account for "low" and "high" levels of both state variables. I choose 1600 million peseta as a cutoff for internal resources, because $10 \%$ of the total number of firms are above this level. Since permanent employment has a strong correlation with internal resources and doing equal cutoffs would leave very few observations for some segments, the cutoff for permanent employment is greater for firms with more internal resources. For firms with 1600 million peseta or less, it is 50 workers and for firms with more than 1600 million peseta it is 300 workers. As this difference makes difficult to compare parameters across different levels of internal resources, these regressions are meant to illustrate if the basic features of the policy rules predicted by the model are found in the data. Accordingly, they should be taken cautiously.

As we have seen in the theoretical section, the signs and amounts of the derivatives of the policy rules depend on the area given by $x_{t}$ and $H_{t}$. Table 4 presents these derivatives based on the simulations of the policy functions presented in the previous section (Two positive signs mean a strong positive effect).

Once the predictions of the model have been established, one can go to the data and test if they fit the data. Table 5 shows a fixed-effects regression of capital next period as a function of the state variables. It can be interpreted as a regression of investment. For any level of resources and of workers, internal resources have a positive and significant effect on capital. This positive effect should be found only for firms with a low level of internal resources, not for firms with a high level of resources and are supposed to be near their desired level of capital. However, it can be seen that both until and after 1987 capital is less sensitive to internal resources for a high level of internal resources and of workers. Following the spirit of the model, one would say that in Spain internal finance has an important influence on investment even for big firms. In other words, even big firms face liquidity constraints, which is equivalent to say that they are not big enough as in other countries. On the other hand, permanent workers tend to have a positive effect on capital next period for a low level of internal resources. The effect for firms with a higher level of resources tends to be negative, though in general not significant. The model predicted no effect for a high level of resources and of workers. It can be the case, however, that big firms have too many permanent workers and that they become a burden on their accumulation of capital. It is also to note, that the importance of permanent workers goes down after 1987.

Table 6 presents a similar fixed-effects regression for permanent workers next period. It shows that permanent employment is sensitive to internal resources for poor firms, whereas for rich firms, as the model predicts, internal resources do not longer influence permanent employment. Coefficients of internal resources are shown to be non-significant for rich firms. The effect of permanent workers is always positive with a higher coefficient for a higher level of permanent workers. That is consistent with Figure 1 and Figure 2, where for a low level of internal resources the slope is bigger when firms have few permanent workers and it is greater when they have more of them. In other words, for low permanent employment, the more internal resources, the lower the persistence of permanent employment. Richer firms, being able to adjust faster to their desired level of permanent workers, exhibit less sensitivity to their level of current permanent workers. At the "inaction zone" the effect is greater, as employment does not need to be adjusted. It is also interesting to see that for poor firms with a low level of permanent workers there is a reduction of persistence of permanent employment, whereas there is an increase in persistence for rich firms. The diffusion of temporary contracts may have reduced this persistence for poor firms, as well as the desired level of permanent workers. This explains also why rich firms exhibit more persistence after 1987. In any case, this regression shows both the effect of liquidity constraints and adjustment costs in permanent employment. If firms did not face liquidity constraints, there would no be any effect of internal resources on permanent workers next period. If there were no adjustment costs, there would be no effect of lagged permanent employment.

Table 7 shows the corresponding regression for temporary workers. Internal resources tend to have a positive effect on temporary workers next period. For rich 
firms the effect tends to be less significant than for poor ones. The effect is especially strong for poor firms with few permanent workers as the model predicts. The effect of permanent workers is negative or zero for poor firms, as the model predicts. That is, the relationship between temporary and lagged permanent workers is characterized by their substitutability. For rich firms with few permanent workers the effect is zero; and for rich firms with more than 300 workers the effect until 1987 is negative, but after 1987 the effect becomes positive. This is evidence for complementarities between permanent and temporary workers once the use of temporary labor consolidates. To account for that complementarity the model would have to relax the assumption of pure substitution between temporary and permanent labor, which is left for a further extension.

Table 8 shows that poor firms exhibit a positive effect of internal resources on debt. For a higher level of internal resources, the effect is positive and non-significant, until 1987; or negative and non-significant, after 1987. As the model predicts an inverted U-shape for debt on internal resources and zero effect for rich firms, both cases are compatible with the predictions of the theoretical model. The effect of permanent workers on debt tends to be positive. For poor firms with few permanent workers, the effect of permanent employment tends to be stronger than for poor firms with a lot of permanent employment. For rich firms with 300 or fewer permanent workers the corresponding effect is negative or non-significant. These findings are also consistent with the predictions of the model presented in Table 4. If there are more than 300 workers and firms are rich the effect becomes positive, which is puzzling, as the predicted effect is zero. The positive effect of permanent workers on debt is partly caused by the expansion of the borrowing limit as firms grow. This table also shows that the sensitivity of debt to permanent workers for poor firms with few permanent workers and for rich firms with high permanent employment, the two modal groups of the sample, decreased substantially after 1987. The introduction of temporary contracts, as temporary labor also enhances the borrowing capacity of firms, may have weakened the connection between permanent employment and debt.

These were reduced-form estimations of the policy rules of the model. An alternative way of verifying the behavior of these variables is to evaluate the contemporaneous relationship of the state variables. This is shown in one estimation for temporary labor. It tries to capture a extended version of Equation (6) which postulates that temporary employment depends negatively on permanent employment, if at all. Since there are many firms that do not hire temporary workers, a Tobit estimation is done and presented in Table 9. Capital has a positive effect on hiring temporary workers, though decreasing in size. Having more permanent workers implies fewer temporary ones. It is clear that bigger firms do not exhibit such a big impact on temporary workers as small ones. This last feature is of particular interest because the descriptive statistics are clear in showing a decrease of temporary employment as a percentage of the labor force as firms grow. Taking models of investment without labor as a baseline and given the assumptions of the theoretical model (as in Pratap \& Rendón (1998)), it seems to be the case that permanent workers follow a similar policy rule as capital (increasing in financial resources and then constant), whereas with temporary workers, the opposite is true: as financial resources increase, they go down as a percentage of the labor force in the firm. However, after 1987 this relationship seems to have gone down, as the parameters of permanent employment are positive. The diffusion of temporary contracts may have made permanent and temporary employment less substitutable. It is also interesting to see in the simulations that temporary workers follow a similar behavior as debt, being first increasing in financial resources, then decreasing and finally zero. ${ }^{3}$ Accordingly, in these regressions debt shows a positive link with temporary employment for small firms and a non-significant effect for bigger ones. As firms decreased contracting debt with respect to internal resources, the positive coefficient also implies a reduction of temporary employment with respect to ${ }^{3}$ This is shown in the simulations and descriptive statistics here and also by Hernando \& Tribó (1999) 
the labor force.

In terms of the theoretical predictions of the model, these results show that most of the features of the data are captured by the model. Internal resources, either directly of through other observable variables, are found to be significant; therefore, the inexistence of liquidity constraints is strongly rejected. Similarly, permanent workers exhibit a clear persistence and dependency on financial resources, so one can reject the inexistence of adjustment costs. Evidence is also provided for the substitutability of permanent workers and of debt by temporary workers, caused by the reform of 1984. The availability of temporary contracts allows firms to accumulate capital faster and to build their staff of permanent workers, reducing thereby the impact of debt of these variables.

\section{Conclusions}

Using a dynamic model of labor demand under liquidity constraints, I showed that Spanish firms use temporary contracts to alleviate financial constraints, reduce their level of borrowing, protect against adverse shocks, and grow faster towards the desired level of permanent workers. Since the creation of permanent jobs is limited by financial restrictions, firms have to improve their financial position to be able to hire more permanent workers and reduce their demand for temporary ones and their need for debt.

In a context of capital and labor market imperfections, like the Spanish economy, the sources of finance are crucial in determining capital and hiring of permanent workers. The reform of 1984 gave small firms a big incentive for creating jobs and meant an indirect relaxation of financial constraints. While temporary job creation increased, there is more permanent job destruction than creation. Because of financial constraints, firms have to build their staff slowly, even if the labor market liberalization had removed all kinds of labor adjustment costs. In this context, small firms are better off with a capital market liberalization than with a labor market liberalization, while for big firms the opposite is true. As most economies are populated mainly by small firms, a job creation strategy that addresses this issue should, therefore, not be restricted to pure labor markets aspects. It should also consider policy measures targeted to relax capital market constraints. 


\section{Appendix: Sample selection}

The data from the Central de Balances del Banco de España (CBBE) are contain information for 94192 observations of 19473 firms. The information consists of balance sheet data, which are mainly financial variables, and employment data. Firms with the following features are excluded out of the sample:

- non-manufacture;

- public;

- that change activity; - that have less than five observations;

- that merge or split.

These filters leave 27704 observations of 3005 firms in the sample. The most important selection is to exclude non-manufacturing firms. With this selection only, 40785 observations of 7587 firms remain in the sample. The next most important selections are to leave out of the sample firms that have observations with the following features:

- value of production $\leq 0$;

- value of net purchases $\leq 0$;

- net material assets $(\mathrm{IMN}) \leq 0$;

- gross capital formation $\leq 0$;

- total alien resources - providers $\leq 0$.

As it is enough that one observation does not pass these filters to exclude the whole firm, after this selection is made, 12336 observations of 1380 firms remain in the sample. Excluding only the observation that does not satisfy the selection criteria would interrupt the sample over time for that firm. However, the database of the CBBE has been designed trying to avoid as much as possible cases that do no make economic sense. In practice, most firms fail to pass these filters because of zero, not because of negative values. Among these filters, the most important is the restriction that gross capital formation be positive. What this means is that firms that remain in the sample are those that are accumulating capital, which is confirmed in Table 1.

The database contains information on balance sheet data, as well as employment data. The definitions of variables used in the paper are based on the following definitions of the database:

- Capital =

net material assets (IMN);

- Investment $=$

Gross fixed capital formation

- Debt = Short term debt with cost;

- Internal resources $=$ Own resources;

- Permanent labor $=$ Number of workers with permanent contracts;

- Temporary labor $=$ Number of workers with temporary contracts.

The original information is given in current million pesetas. I use the industrial price index to deflate the data in pesetas of 1987. Table 10 shows the structure of the panel by year. There is a relatively fair representation of all periods of interest in the sample. The first two years, 1983 and 1984, have relatively fewer observations than the other years. Since 1984 is the year of the labor reform that introduced temporary contracts, it would be desirable to have relatively more data for early years of the sample. Table 11 shows the number of observations per firm in the panel. It gives an idea of the longitudinal dimension of the panel and shows a fair amount of observations per firm. For almost half of the sample there are 10 or more observations per firm, which means that a relatively big proportion of firms stay in the sample for a long time. This fact can compensate for the existence of few data in 1984. 


\section{References}

Aguirregabiria, V. \& Alonso-Borrego, C. (1998), Labor contracts and flexibility: Evidence from a Spanish labor market reform, mimeo.

Alonso-Borrego, C. \& Bentolila, S. (1994), 'Investment and Q in Spanish manufacturing firms', Oxford Bulletin of Economics and Statistics 56, 49-65.

Bentolila, S. \& Dolado, J. J. (1993), La contratación temporal y sus efectos sobre la competitividad, Banco de España. Servicio de Estudios. Documento de Trabajo No. 9319 .

Bentolila, S. \& Saint-Paul, G. (1992), A model of labour demand with linear adjusment costs, Centre for Economic Policy Research. Discussion Paper No 690.

Bover, O., Arellano, M. \& Bentolila, S. (1997), Unemployment duration, benefit duration, and the business cycle, CEMFI. Working Paper No 9717.

Caballero, R. (1997), Aggregate investment, Massachusetts Institute of Technology. Working Paper97/2.

Dolado, J. J. \& Bentolila, S. (1992), Who are the insiders? wage setting in Spanish manufacturing firms, Banco de España. Servicio de Estudios. Documento de Trabajo No. 9229.

Estrada, A. \& Vallés, J. (1995), Inversión y costes financieros: evidencia en España con datos de panel, Banco de España. Servicio de Estudios. Documento de Trabajo No. 9506 .

Gómez, R. \& Dolado, J. J. (1995), Creación y destrucción de empleo en España: un análisis descriptivo con datos de la CBBE, Banco de España. Servicio de Estudios. Documento de Trabajo No. 9526.
Greenwald, B. C., Stiglitz, J. E. \& Weiss, A. (1984), 'Informational imperfections in the capital market and macroeconomic fluctuations', American Economic Review 74, 194-200.

Gross, D. (1994), The investment and financing decisions of liquidity constrained firms, mimeo, Massachusetts Institute of Technology.

Hernando, I. \& Tribó, J. A. (1999), Relación entre contratos laborales y financieros: Un estudio teórico y empírico aplicado para el caso español, Banco de España. Servicio de Estudios. Dcoumento de Trabajo No 9904.

Jorgenson, D. W. (1963), 'Capital theory and investment behavior', American Economic Review 33, 247-259.

Myers, S. C. \& Majluf, N. S. (1984), 'Corporate financing and investment decisions when firms have information that investors do not have', Journal of Financial Economics 13, 187-221.

Pratap, S. \& Rendón, S. (1998), Firm investment in imperfect capital markets: A structural estimation, Universitat Pompeu Fabra. Working Paper 274. 
Table 1: Descriptive Statistics

\begin{tabular}{|c|c|c|c|c|c|c|c|}
\hline \multirow{2}{*}{\multicolumn{2}{|c|}{ Variable }} & \multicolumn{2}{|c|}{ All } & \multicolumn{2}{|c|}{ Low $\mathrm{x}$} & \multicolumn{2}{|c|}{ High $\mathrm{x}$} \\
\hline & & Mean & St. Dev. & Mean & t. Dev. & Mean & St. Dev. \\
\hline Observations & & \multicolumn{2}{|c|}{$\begin{array}{l}12336 \\
\end{array}$} & \multicolumn{2}{|c|}{ " } & \multicolumn{2}{|c|}{$\begin{array}{ll}1492 \\
\end{array}$} \\
\hline Capital & $K$ & 881.86 & 4259.61 & 232.64 & 328.33 & 5600.42 & 11134.54 \\
\hline Permanent Labor & $\mathrm{H}$ & 185.62 & 866.52 & 72.24 & 84.28 & 1009.64 & 2321.03 \\
\hline Temporary Labor & $\mathrm{L}$ & 20.36 & 57.65 & 13.19 & 33.73 & 72.50 & 126.98 \\
\hline Debt & B & 445.27 & 2428.87 & 169.25 & 292.86 & 2451.44 & 6603.05 \\
\hline Own resources & $\mathrm{x}$ & 1780.14 & 8341.54 & 326.60 & 350.26 & 8583.19 & 17738.15 \\
\hline \multicolumn{2}{|l|}{ Ratios } & 1.503 & 1.003 & 1.404 & 1.316 & 1.533 & .885 \\
\hline \multicolumn{2}{|l|}{$B / K$} & 0.505 & 0.649 & 0.728 & 1.026 & 0.438 & 0.460 \\
\hline \multicolumn{2}{|l|}{$x / N$} & 6.434 & 8.337 & 3.823 & 3.585 & 7.932 & 9.793 \\
\hline \multicolumn{2}{|l|}{$K / N$} & 4.281 & 5.200 & 2.723 & 2.807 & 5.175 & 5.988 \\
\hline \multicolumn{2}{|l|}{$B / N$} & 2.162 & 3.013 & 1.981 & 2.451 & 2.265 & 3.289 \\
\hline \multicolumn{2}{|l|}{$L / N$} & 0.099 & 0.160 & 0.154 & 0.202 & 0.067 & 0.118 \\
\hline \multicolumn{2}{|l|}{ Growth (in \%) } & & & & & & \\
\hline \multicolumn{2}{|l|}{$g^{K}=I / K$} & 18.93 & 14.40 & 21.72 & 19.61 & 18.09 & 12.26 \\
\hline \multirow{2}{*}{\multicolumn{2}{|c|}{$g^{N}=\Delta N / N$}} & -0.57 & 12.53 & 1.54 & 15.89 & -1.75 & 9.98 \\
\hline & & -1.36 & 12.03 & 0.25 & 15.34 & -2.17 & 9.84 \\
\hline \multicolumn{2}{|l|}{$\Delta L / L$} & 3.45 & 67.68 & 5.13 & 68.53 & 1.23 & 66.50 \\
\hline \multicolumn{2}{|l|}{$\begin{array}{l}\operatorname{cor}\left(g_{t}^{K}, g_{t+1}^{K}\right) \\
\operatorname{cor}\left(g_{t}^{N}, g_{t+1}^{N}\right)\end{array}$} & \multicolumn{2}{|c|}{$\begin{array}{l}0.4314 \\
0.0834\end{array}$} & \multicolumn{2}{|c|}{0.3142} & \multicolumn{2}{|c|}{0.5144} \\
\hline
\end{tabular}

Note 1: Total Labor: $N=(H+L)$

Note 2: With the exception of labor, all data are given in million pesetas of 1987.
Table 2: Temporary workers over the labor force(\%) by year and by firm's size

\begin{tabular}{r|rrrrr|r}
\hline \hline Year & \multicolumn{5}{|c|}{ Workers per firm } & \\
& {$[0,50]$} & $(50,100]$ & $(100,500]$ & $(500,1000]$ & $1000+$ & Total \\
\hline \hline 1983 & 4.67 & 7.12 & 5.14 & 4.20 & 1.76 & 3.39 \\
1984 & 6.19 & 5.71 & 5.91 & 4.62 & 2.20 & 3.95 \\
1985 & 7.23 & 8.13 & 6.81 & 9.26 & 0.98 & 4.55 \\
1986 & 8.51 & 9.17 & 9.11 & 9.80 & 2.09 & 6.39 \\
1987 & 11.46 & 10.70 & 10.92 & 9.31 & 4.13 & 7.86 \\
1988 & 12.22 & 15.83 & 13.91 & 15.29 & 5.01 & 10.35 \\
1989 & 16.32 & 15.42 & 16.31 & 15.82 & 8.38 & 12.63 \\
1990 & 16.07 & 19.58 & 17.10 & 13.46 & 7.58 & 12.78 \\
1991 & 17.59 & 21.12 & 17.88 & 16.83 & 5.47 & 12.49 \\
1992 & 19.31 & 23.71 & 18.60 & 17.64 & 7.10 & 13.97 \\
1993 & 20.61 & 21.24 & 16.93 & 13.23 & 5.58 & 11.92 \\
1994 & 21.46 & 21.62 & 17.43 & 15.25 & 5.25 & 11.92 \\
1995 & 22.21 & 22.33 & 19.68 & 15.50 & 5.08 & 12.41 \\
1996 & 21.51 & 23.14 & 19.79 & 18.69 & 4.42 & 12.35 \\
\hline \hline Total & 15.71 & 16.43 & 13.74 & 13.06 & 4.71 & 9.88 \\
\hline \hline
\end{tabular}

Table 3: Debt-Capital Ratio by year and firm's size

\begin{tabular}{l|rrrrr|r}
\hline \hline Year & \multicolumn{5}{|c|}{ Workers per firm } & \\
& {$[0,50]$} & $(50,100]$ & $(100,500]$ & $(500,1000]$ & $1000+$ & Total \\
\hline \hline 1983 & .3765 & .5579 & .5199 & .6093 & .6940 & .6264 \\
1984 & .5335 & .8327 & .5652 & .6994 & .8411 & .7387 \\
1985 & .5246 & 1.0306 & .6280 & .7029 & .7610 & .7161 \\
1986 & .6243 & .9394 & .5176 & .6263 & .6280 & .6083 \\
1987 & .5722 & .7466 & .5278 & .5843 & .5899 & .5759 \\
1988 & .6219 & .8073 & .4918 & .5764 & .3738 & .4658 \\
1989 & .5585 & .7538 & .5334 & .4636 & .2644 & .4167 \\
1990 & .5152 & .6149 & .5273 & .6644 & .3548 & .4695 \\
1991 & .5900 & .6352 & .5418 & .5053 & .3718 & .4679 \\
1992 & .5654 & .7276 & .5812 & .5632 & .3280 & .4661 \\
1993 & .6059 & .6853 & .5627 & .5605 & .4119 & .4960 \\
1994 & .5535 & .6866 & .5131 & .4723 & .2969 & .4078 \\
1995 & .5948 & .6911 & .4287 & .4659 & .3231 & .4019 \\
1996 & .6012 & .6034 & .3479 & .3148 & .3277 & .3625 \\
\hline \hline Total & .5682 & .7218 & .5209 & .5412 & .4600 & .5049 \\
\hline \hline
\end{tabular}




\begin{tabular}{|c|c|c|c|c|}
\hline & \multicolumn{2}{|c|}{ Low $x_{t}$} & \multicolumn{2}{|c|}{ High $x_{t}$} \\
\hline & Low $H_{t}$ & $\operatorname{High} H_{t}$ & Low $H_{t}$ & $\operatorname{High} H_{t}$ \\
\hline$\frac{\partial K_{t+1}}{\partial x_{t}}$ & + & ++ &,++ 0 &,+ 0 \\
\hline$\frac{\partial K_{t+1}}{\partial H_{t}}$ & + &,+ 0 & 0 &,+ 0 \\
\hline$\frac{\partial H_{t+1}}{\partial x_{t}}$ & + & $0,-;$ &,++ 0 & 0 \\
\hline$\frac{\partial H_{t+1}}{\partial H_{t}}$ & + & ++ &,+ 0 & $0,+$ \\
\hline$\frac{\partial L_{t+1}}{\partial x_{t}}$ & + & 0 &,- 0 & 0 \\
\hline$\frac{\partial L_{t+1}}{\partial H_{t}}$ & $-;$ & 0 & 0 & 0 \\
\hline$\frac{\partial B_{t+1}}{\partial x_{t}}$ &,$+-;$ &,++-- & 0 &,- 0 \\
\hline$\frac{\partial B_{t+1}}{\partial H_{t}}$ &,+ 0 & 0 &,+ 0 & 0. \\
\hline
\end{tabular}

Table 5: Capital Next Period

(Fixed effects regression)

\begin{tabular}{|c|c|c|c|c|}
\hline \multirow{3}{*}{ Variable } & \multicolumn{2}{|c|}{ 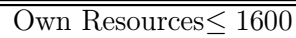 } & \multicolumn{2}{|c|}{ 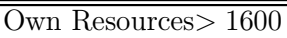 } \\
\hline & \multicolumn{2}{|c|}{ Permanent Workers } & \multicolumn{2}{|c|}{ Permanent Workers } \\
\hline & {$[0,50]$} & $50+$ & {$[0,300]$} & $300+$ \\
\hline \multirow{3}{*}{$x_{t}$} & & \multicolumn{2}{|c|}{$\leq 1987$} & \\
\hline & 0.286 & 0.335 & 0.332 & 0.117 \\
\hline & $(0.011)$ & $(0.009)$ & & $(0.017)$ \\
\hline \multirow{4}{*}{$H_{t}$} & 25.73 & 38.56 & 3.75 & 7.03 \\
\hline & 2.146 & 0.566 & -5.799 & -0.341 \\
\hline & $(0.206)$ & $(0.170)$ & $(3.583)$ & $(0.243)$ \\
\hline & 10.42 & 3.33 & -1.62 & -1.40 \\
\hline Nobs & 1528 & 1846 & 95 & 323 \\
\hline $\mathrm{F}$ & 644.15 & 980.51 & 7.07 & 31.74 \\
\hline \multirow[t]{2}{*}{$R^{2}$} & 0.4578 & 0.52 & 0.13 & 0.17 \\
\hline & \multicolumn{3}{|c|}{$>1987$} & \\
\hline \multirow[t]{2}{*}{$x_{t}$} & 0.282 & 0.244 & 0.349 & 0.173 \\
\hline & $(0.011)$ & $(.018)$ & $(0.041)$ & $(0.018)$ \\
\hline & 24.73 & 13.47 & 8.46 & 9.58 \\
\hline \multirow[t]{3}{*}{$H_{t}$} & 0.274 & 0.523 & -1.105 & -2.228 \\
\hline & $(0.150)$ & $(.170)$ & $(0.794)$ & $(0.266)$ \\
\hline & 1.83 & 3.07 & -1.39 & -8.37 \\
\hline Nobs & 3954 & 2321 & 370 & 519 \\
\hline $\mathrm{F}$ & 339.56 & 105.45 & 35.80 & 89.64 \\
\hline$R^{2}$ & 0.15 & 0.08 & 0.16 & 0.26 \\
\hline
\end{tabular}

Note: $\overline{\text { Standard errors in parenthesis; t-statistic below standard }}$ error. 
Table 6: Permanent Workers Next Period

Fixed effects regression)

Own Resources $\leq 1600$ Own Resources $>1600$

\begin{tabular}{|c|c|c|c|c|}
\hline \multirow{3}{*}{ Variable } & \multicolumn{2}{|c|}{ Own Resources $\leq 1600$} & \multicolumn{2}{|c|}{ Own Resources> $>1600$} \\
\hline & \multicolumn{2}{|c|}{ Permanent Workers } & \multicolumn{2}{|c|}{ Permanent Workers } \\
\hline & {$[0,50]$} & $50+$ & {$[0,300]$} & $300+$ \\
\hline & & \multicolumn{2}{|c|}{$=1987$} & \\
\hline \multirow{3}{*}{$x_{t}$} & 0.004 & 0.002 & 0.001 & 0.000 \\
\hline & $(0.001)$ & $(0.001)$ & $(0.002)$ & $(0.001)$ \\
\hline & 4.65 & 2.31 & 0.29 & 0.38 \\
\hline \multirow[t]{3}{*}{$H_{t}$} & 0.638 & 0.739 & 0.404 & 0.887 \\
\hline & $(0.018)$ & $(0.015)$ & $(0.088)$ & $(0.015)$ \\
\hline & 35.61 & 50.37 & 4.62 & 59.52 \\
\hline Nobs & 1528 & 1846 & 95 & 323 \\
\hline $\mathrm{F}$ & 912.9 & 1611.56 & 14.89 & 1951.02 \\
\hline \multirow[t]{2}{*}{$R^{2}$} & 0.55 & 0.64 & 0.24 & 0.92 \\
\hline & & \multicolumn{2}{|c|}{$>1987$} & \\
\hline \multirow[t]{3}{*}{$x_{t}$} & 0.004 & 0.005 & 0.003 & 0.001 \\
\hline & $(0.001)$ & $(0.002)$ & $(0.002)$ & $(0.001)$ \\
\hline & 4.47 & 2.86 & 1.96 & 1.14 \\
\hline \multirow[t]{3}{*}{$H_{t}$} & 0.527 & 0.727 & 0.455 & 0.961 \\
\hline & $(0.011)$ & $(0.018)$ & $(0.033)$ & $(0.016)$ \\
\hline & 45.98 & 41.16 & 13.99 & 58.54 \\
\hline Nobs & 3954 & 2321 & 370 & 519 \\
\hline $\mathrm{F}$ & 1190.79 & 896.86 & 105.88 & 1724.14 \\
\hline$R^{2}$ & 0.38 & 0.44 & 0.37 & 0.87 \\
\hline
\end{tabular}

Note $\overline{R^{2} \text { Standard errors in parenthesis; t-statistic below standard }}$ rror
Table 7: Temporary Workers Next Period (Fixed effects regression)

\begin{tabular}{|c|c|c|c|c|}
\hline \multirow{3}{*}{ Variable } & \multicolumn{2}{|c|}{ Own Resources $\leq 1600$} & \multicolumn{2}{|c|}{ Own Resources $>1600$} \\
\hline & \multicolumn{2}{|c|}{ Permanent Workers } & \multicolumn{2}{|c|}{ Permanent Workers } \\
\hline & {$[0,50]$} & $50+$ & {$[0,300]$} & $300+$ \\
\hline & & \multicolumn{2}{|c|}{$\leq 1987$} & \\
\hline \multirow[t]{2}{*}{$x_{t}$} & 0.014 & 0.020 & 0.001 & 0.003 \\
\hline & $(0.001)$ & $(0.001)$ & $(0.002)$ & $(0.001)$ \\
\hline & 12.12 & 17.72 & 0.63 & 4.82 \\
\hline \multirow[t]{3}{*}{$H_{t}$} & -0.077 & 0.038 & -0.111 & -0.024 \\
\hline & $(0.022)$ & $(0.023)$ & $(0.083)$ & $(0.008)$ \\
\hline & -3.52 & 1.68 & -1.33 & -3.16 \\
\hline Nobs & 1528 & 1846 & 95 & 323 \\
\hline $\mathrm{F}$ & 76.04 & 208.61 & 0.89 & 23.59 \\
\hline \multirow[t]{2}{*}{$R^{2}$} & 0.09 & 0.19 & 0.02 & 0.13 \\
\hline & & \multicolumn{2}{|c|}{$=>1987$} & \\
\hline \multirow[t]{3}{*}{$x_{t}$} & 0.015 & 0.010 & 0.009 & 0.002 \\
\hline & $(0.001)$ & $(0.002)$ & $(0.002)$ & $(0.001)$ \\
\hline & 12.64 & 4.18 & 3.87 & 1.94 \\
\hline \multirow[t]{3}{*}{$H_{t}$} & -0.064 & 0.042 & -0.049 & 0.045 \\
\hline & $(0.016)$ & $(0.022)$ & $(0.043)$ & $(0.011)$ \\
\hline & -3.99 & 1.91 & -1.12 & 3.96 \\
\hline Nobs & 3954 & 2321 & 370 & 519 \\
\hline $\mathrm{F}$ & 80.3 & 12.26 & 7.65 & 9.04 \\
\hline$R^{2}$ & 0.04 & 0.01 & 0.04 & 0.03 \\
\hline
\end{tabular}

Note: Standard errors in parenthesis; t-statistic below standard 
Table 8: Debt Next Period

(Fixed effects regression)

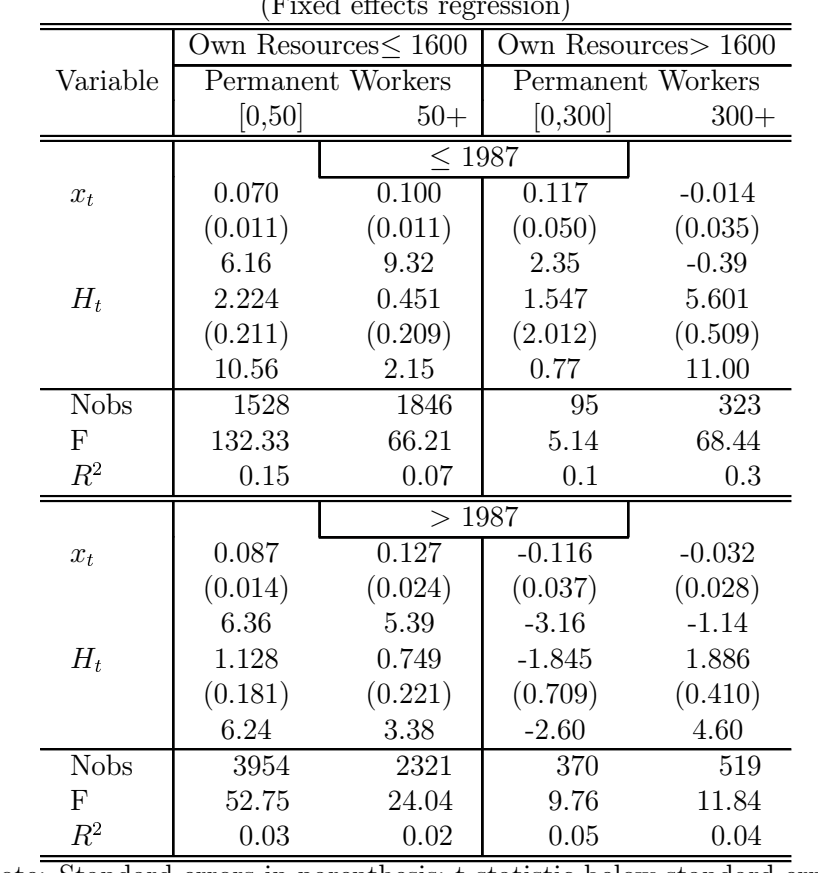

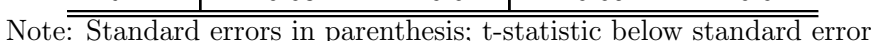

Table 9: Tobit Estimates for Temporary Workers

\begin{tabular}{l|cc|cc}
\hline \hline \multirow{2}{*}{ Variable } & \multicolumn{2}{|c|}{ Obs of 1987 and before } & \multicolumn{2}{|c}{ Obs after 1987 } \\
\cline { 2 - 5 } & \multicolumn{2}{|c}{ Own resources } & \multicolumn{2}{c}{ Own resources } \\
& $\leq 1600$ & $>1600$ & 0.011 & $>1600$ \\
\hline \hline $\mathrm{K}$ & .021 & 0.001 & $(0.002)$ & $(0.005)$ \\
& $(0.004)$ & $(0.001)$ & 6.43 & 5.93 \\
$\mathrm{H}$ & 5.31 & 0.87 & & \\
& & & & \\
& -.023 & -0.0001 & 0.007 & -0.007 \\
& $(0.011)$ & $(0.003)$ & $(0.008)$ & $(0.004)$ \\
$\mathrm{B}$ & -2.04 & -0.05 & 0.94 & -1.76 \\
& & & & \\
& 0.041 & -0.001 & 0.041 & -0.001 \\
const. & $(0.004)$ & $(0.001)$ & $(0.002)$ & $(0.001)$ \\
& 9.99 & -1.10 & 22.27 & -0.80 \\
& & & & \\
$\sigma$ & -22.383 & 11.984 & -2.472 & 50.578 \\
& $(1.421)$ & $(5.631)$ & $(0.606)$ & $(5.350)$ \\
& -15.75 & 2.13 & -4.08 & 9.45 \\
& & & & \\
Log-Likelihood & -10389.34 & -1796.04 & -28886.32 & -5943.27 \\
Nobs & 3415 & 421 & 7429 & 1071 \\
Unsored & 1644 & 137 & 1975 & 171 \\
Uncensored & 1771 & 284 & 5454 & 900 \\
\hline \hline
\end{tabular}

Note: Standard errors in parenthesis; t-statistic below standard error. 
Table 10: Structure of the panel by year

\begin{tabular}{rrrr}
\hline \hline Year & Obs. & Freq. & Cumulative \\
\hline \hline 1983 & 495 & 4.01 & 4.01 \\
1984 & 609 & 4.94 & 8.95 \\
1985 & 745 & 6.04 & 14.99 \\
1986 & 939 & 7.61 & 22.60 \\
1987 & 1048 & 8.50 & 31.10 \\
1988 & 1062 & 8.61 & 39.70 \\
1989 & 1060 & 8.59 & 48.30 \\
1990 & 1024 & 8.30 & 56.60 \\
1991 & 966 & 7.83 & 64.43 \\
1992 & 956 & 7.75 & 72.18 \\
1993 & 925 & 7.50 & 79.68 \\
1994 & 873 & 7.08 & 86.75 \\
1995 & 859 & 6.96 & 93.72 \\
1996 & 775 & 6.28 & 100.00 \\
\hline \hline Total & 12336 & 100.00 & \\
\hline \hline
\end{tabular}

Table 11: Balance of the Panel

\begin{tabular}{rrrrrrr}
\multicolumn{7}{c}{ Table 11: Balance of the Panel } \\
\hline \hline $\begin{array}{r}\text { Obs. } \\
\text { by firm }\end{array}$ & Obs. & $\%$ & Cum. & Firms & $\%$ & Cum. \\
\hline \hline 5 & 1140 & 9.24 & 9.24 & 228 & 16.52 & 16.52 \\
6 & 1170 & 9.48 & 18.73 & 195 & 14.13 & 30.65 \\
7 & 819 & 6.64 & 25.36 & 117 & 8.48 & 39.13 \\
8 & 1088 & 8.82 & 34.18 & 136 & 9.86 & 48.99 \\
9 & 1089 & 8.83 & 43.01 & 121 & 8.77 & 57.75 \\
10 & 1230 & 9.97 & 52.98 & 123 & 8.91 & 66.67 \\
11 & 1397 & 11.32 & 64.31 & 127 & 9.20 & 75.87 \\
12 & 1140 & 9.24 & 73.55 & 95 & 6.88 & 82.75 \\
13 & 897 & 7.27 & 80.82 & 69 & 5.00 & 87.75 \\
14 & 2366 & 19.18 & 100.00 & 169 & 12.25 & 100.00 \\
\hline \hline Total & 12336 & 100.00 & & 1380 & 100.00 & \\
\hline \hline
\end{tabular}




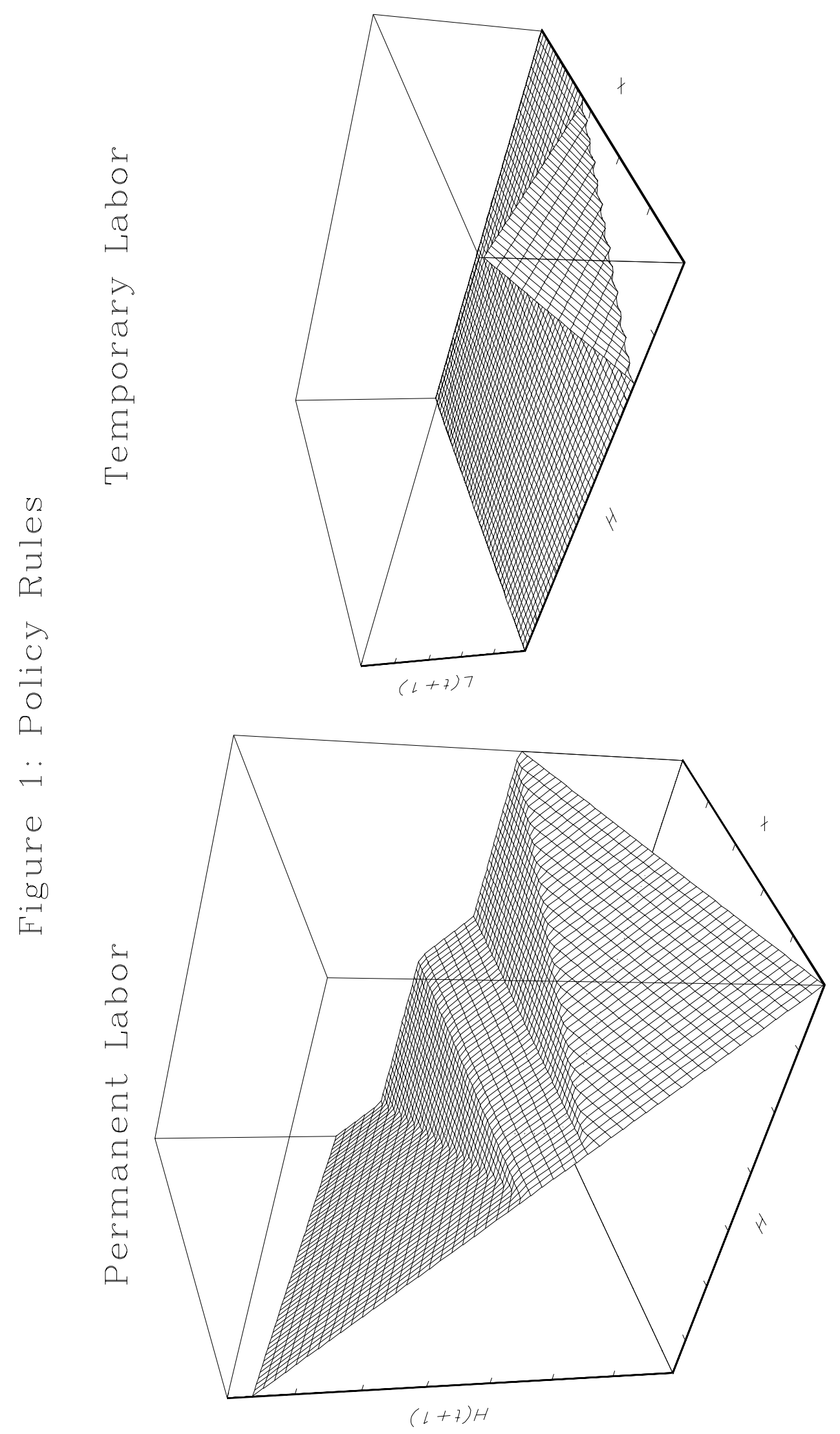



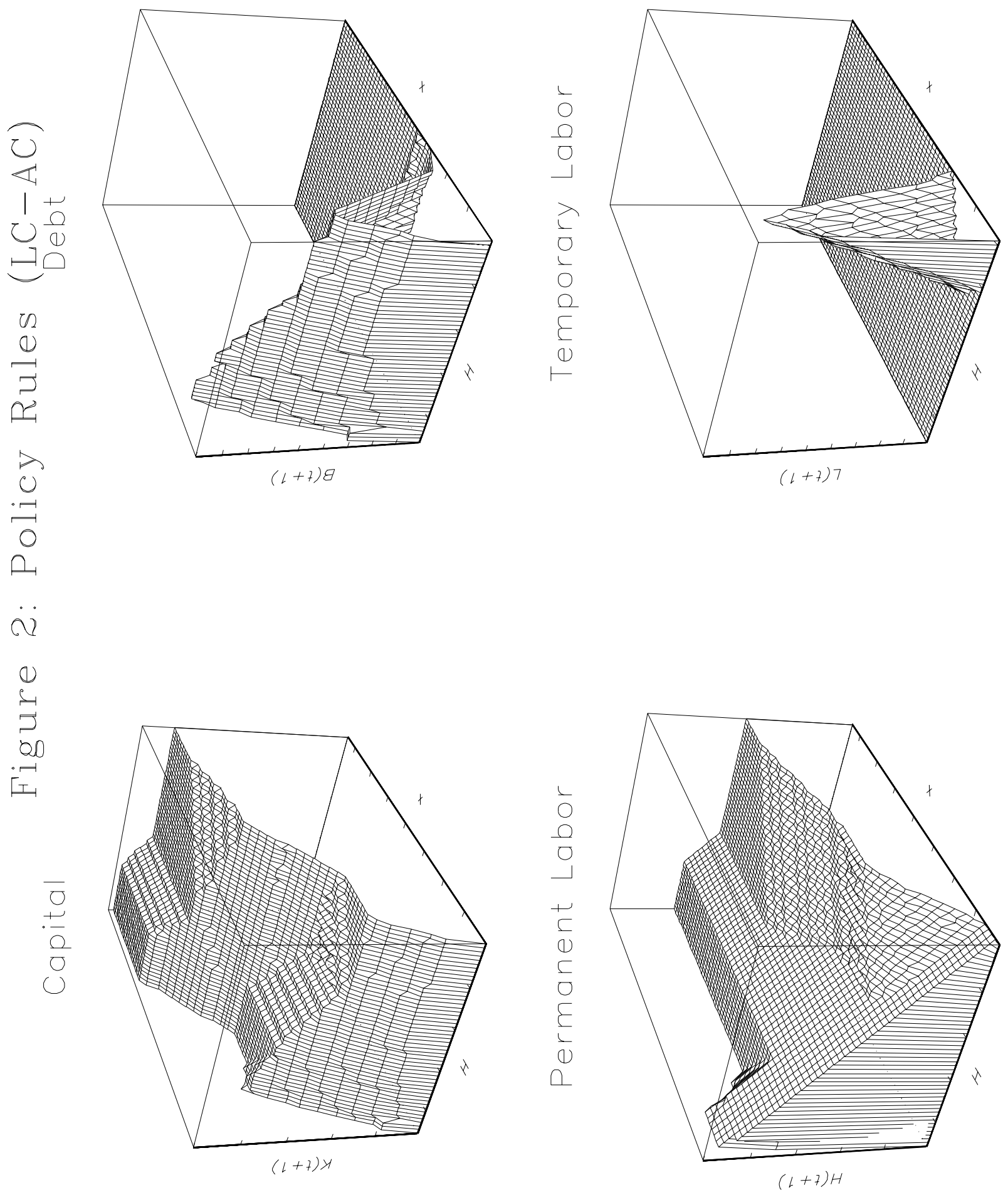

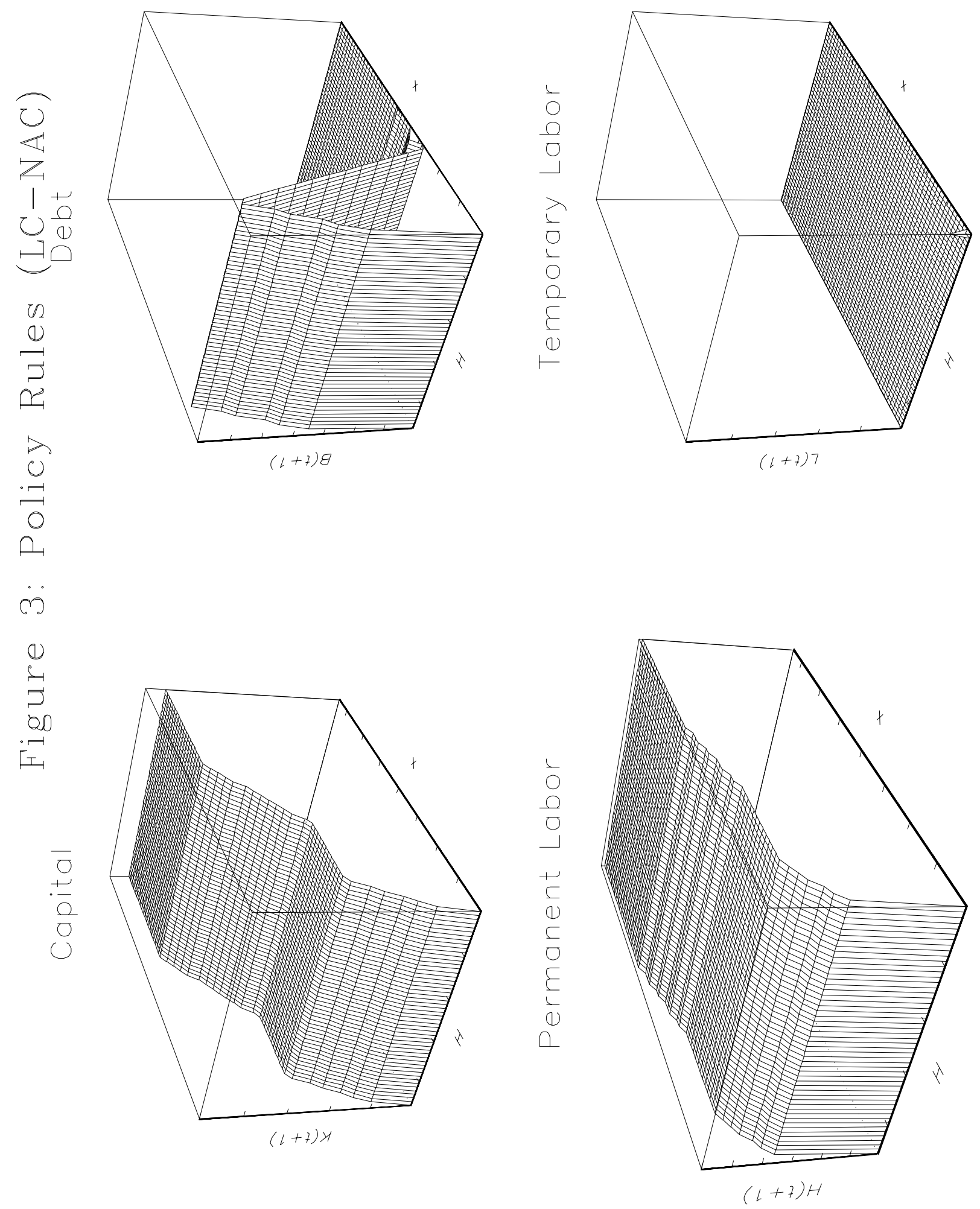

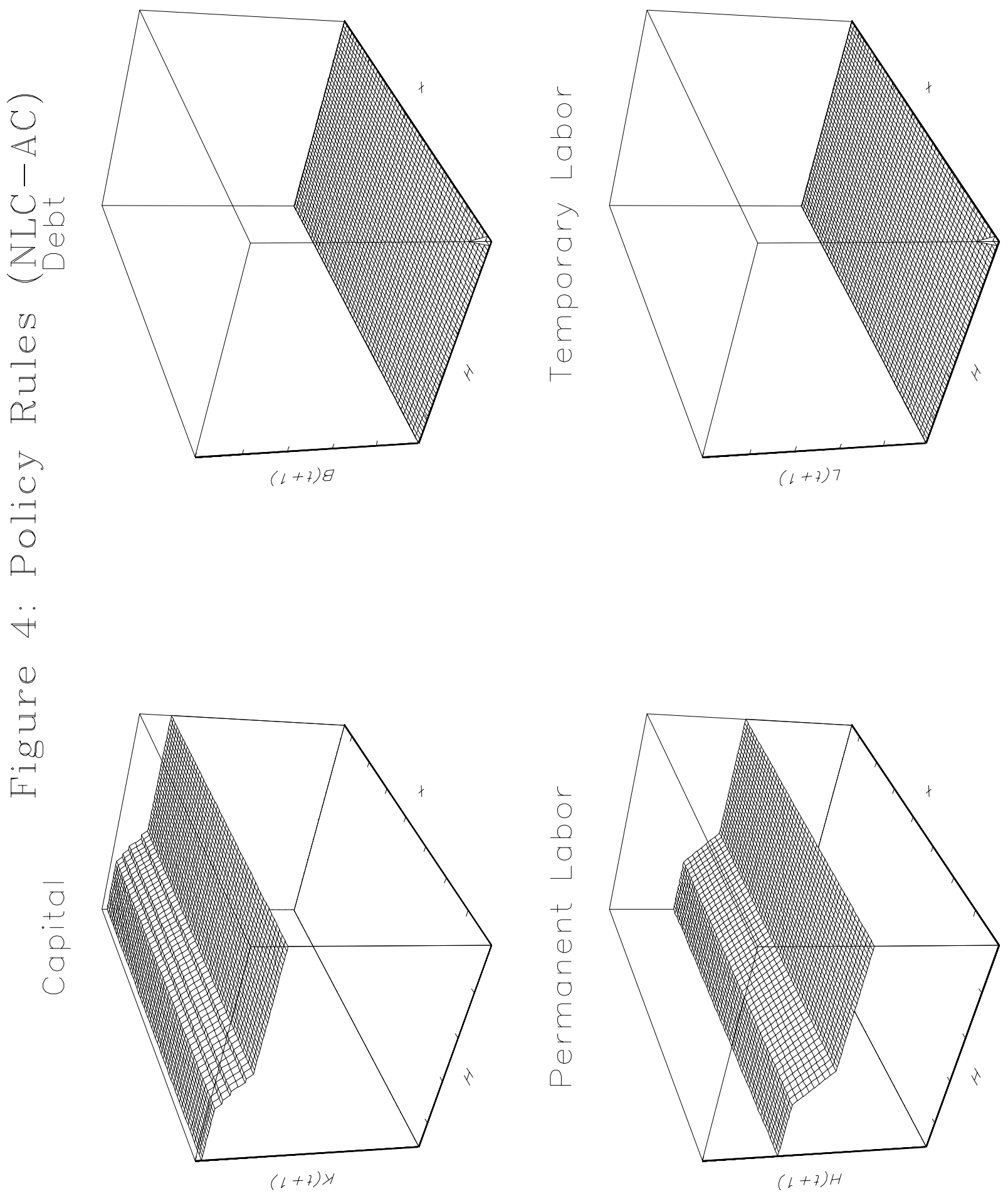

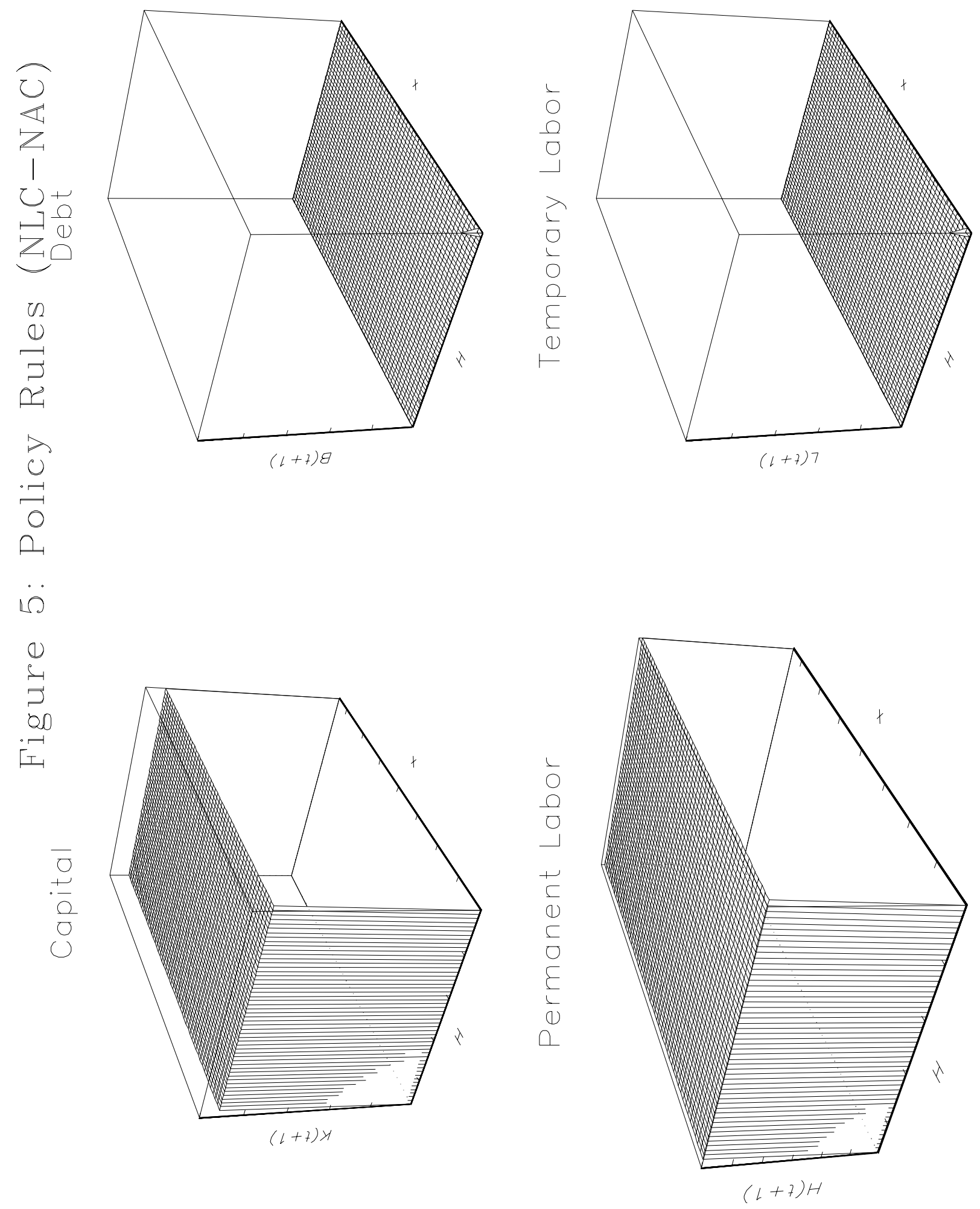